\title{
PI anti-windup speed control of Permanent Magnet Synchronous Motor based on feedforward compensation
}

\author{
Yernar Zhetpissov, Azamat Kaibaldiyev, and Ton Duc Do \\ Department of Robotics and Mechatronics School of Science and Technology \\ Nazarbayev University \\ Astana Z05H0P9, Kazakhstan \\ doduc.ton@nu.edu.kz
}

\begin{abstract}
This paper designs simulation model of PI anti-windup speed controller based on a simple set-point weighting for the interior permanent-magnet synchronous motor (IPMSM). Firstly, a mathematical model of IPMSM drive system utilized in the simulation is introduced. Also, the maximum torque per ampere (MTPA) control suitable for IPMSM was employed. This controller is simple for implementation in practice and it has advantages over a conventional PI controller. The proposed anti-windup PI controller demonstrates better dynamic step changes response in speed in terms of overshoots, improved settling time, and improved robustness to parameter variations in comparison with conventional PI. The performance of proposed PI anti-windup controller with set-point weighting was compared with the conventional PI
\end{abstract}

Keywords-IPMSM, PI, speed control, anti-windup, feedforward, tracking, back calculation, set-point weighting

\section{INTRODUCTION}

In recent time, permanent magnet synchronous motor (PMSM) is getting more popular in terms of its pros in efficient power to rate ratio, robustness, low noise, power and efficiency in comparison to AC motors [3]-[4], [9][11]. Basically, there are two types of PMSM: surfacemounted PMSM (SPMSM) and interior PMSM (IPMSM). However, of two, IPMSM is more advantageous than SPMSM. In particular, the IPMSM in comparison to SPMSM is suitable for higher speeds, which is achieved by the flux-weakening technique that IPMSM can stand by a strong structure of rotor as well as an air gap, which is small enough for efficiency [11]. Moreover, the IPMSM is able to produce more torque than SPMSM because IPMSM has reluctance torque in addition to the electromagnetic torque. This reluctance torque is present in IPMSM because the magnets embedded into rotor makes the quadrature-axis inductance $\left(L_{d}\right)$ larger than the direct-axis inductance $\left(L_{d}\right)$ [8].

On the other hand, IPMSM becomes more nonlinear system because $d-q$ axis currents and d-q axis inductances act on each other due to the presence of reluctance torque, which is not the case in SPMSM [12]. Therefore, during high-performance usage, the challenge arises with the accuracy of the IPMSM drives control. System uncertainties and disturbances are common problems in IPMSM along with nonlinearity [8]. Thus, to solve above challenges, high-performance control is needed, which in turn will give a quick transient response, speed stabilization from various disturbances and firmness to parameter changes. However, high performance cannot be obtained by conventional methods of control like proportional-integral (PI), linear quadratic regulator (LQR) [12]. Thus, more advanced control methods which include fuzzy control [16], hybrid-fuzzy control [1], vector control [2], model predictive control [17], slidingmode control [15], adaptive control [14] and internal mode control [13] have been investigated. For [13]-[14], by changing d-axis current to zero value, control system design of IPMSM can be made easier. But it will cause the reluctance torque to disappear and subsequently, IPMSM will not produce maximized torque. Higher torque with low current consumption can be achieved for control method as in [16] by efficient application of reluctance torque with the use of maximum torque per ampere (MTPA) operation. Even though the fuzzy control is popular research focus, its control algorithm becomes complex as fuzzy rules grow [5]. Also, such control methods possess several thresholds to choose suitable membership functions and fuzzy rules. The design process needed by the predictive control model is very complex [17].

The PI anti-windup speed controller technique has been investigated for a long time. It proposes short settling time, smooth tracking and absence of overshoot in transient response [6]. Adding feedforward term makes its tracking performance to be substantially improved [3]. However, the robustness of such controller to parameter variations is a topic for further investigation.

This paper presents PI anti-windup speed control of IPMSM based on feedforward compensation with tracking and back calculation. This speed controller accounts for nonlinear effects of a control system. The proposed advanced speed controller was tested via mathematical simulation in a Matlab/Simulink software. 


\section{ANTI-WINDUP PI CONTROLleR With SETPOINT WEIGHTS DESIGN}

\section{A. Dynamic Model of IPMSM}

The mathematical model of a 3-phase IPMSM servo system in the d-q reference frame is represented by the given equations:

$$
\left\{\begin{array}{c}
\dot{\omega}=k_{1} i_{q s}-k_{2} \omega-k_{3} T_{L}+k_{11} i_{d s} i_{q s} \\
i_{q s}=-k_{4} i_{q s}-k_{5} \omega+k_{6} V_{q s}-k_{10} \omega i_{d s} \\
l_{d s}=-k_{7} i_{d s}+k_{8} V_{d s}+k_{9} \omega i_{q s}
\end{array}\right.
$$

where

$$
\begin{array}{llll}
k_{1}=\frac{3}{2} \frac{1}{J} \frac{p^{2}}{4} \lambda_{m} & k_{2}=\frac{B}{J} \quad k_{3}=\frac{p}{2 J} & k_{4}=\frac{R_{s}}{L_{q}} \\
k_{5}=\frac{\lambda_{m}}{L_{q}} & k_{6}=\frac{1}{L_{q}} \quad k_{7}=\frac{R_{s}}{L_{d}} & k_{8}=\frac{1}{L_{d}} & k_{9}=\frac{L_{q}}{L_{d}} \\
k_{10}=\frac{L_{d}}{L_{q}} & k_{11}=\frac{3}{2} \frac{1}{J} \frac{p^{2}}{4}\left(L_{d}-L_{q}\right) &
\end{array}
$$

$\omega$ is the electrical rotor speed, $i_{d s}$ and $i_{q s}$ are the d-axis and q-axis currents, $V_{d s}$ and $V_{q s}$ are the d-axis and qaxis voltages, $T_{L}$ is the load torque, $\mathrm{p}$ is the number of poles, $R_{s}$ is the stator resistance, $L_{d}$ and $L_{q}$ are the daxis and q-axis inductances, $\mathrm{J}$ is the rotor inertia, B is the viscous friction coefficient, $\lambda_{m}$ is the magnetic flux linkage.

$\omega, i_{d s}$ and $i_{q s}$ are measurable state variables, $V_{d s}$ and $V_{q s}$ are the control inputs, $T_{L}$ is considered as the disturbance.

\section{B. Implementation of a MTPA method}

The d-axis current reference $i_{d s d}$ is frequently equated to zero with an intention to simplify the controller design. However, this approach does not allow to maximize the torque generation. Utilizing of the MTPA approach is able to increase the torque produced in the constant torque region and overall drive efficiency. The following approximate equation was used in the model to obtain desired d-axis current.

$$
i_{q s d}=\frac{L_{d}-L_{q}}{\lambda_{m}} i_{q s}^{2}
$$

\section{Anti-windup and 2DOF approaches}

Sudden significant change in reference speed, large disturbances or equipment malfunction can result in an excess amount of current and voltage, which in turn can damage a motor, cause long settling time, produce big overshoots, and sometimes makes the system unstable. This undesirable system behavior is called integratorwindup [6]. The windup phenomenon can be avoided by incorporation into speed controller of an anti-windup technique.

The anti-windup compensators have several variations such as back-calculation and tracking, integrator reset and low-order dynamic compensator. The back-calculation and tracking technique is easy to implement and apply in most of the electronic drives including IPMSM motor speed controller.
The principle of back-calculation approach is as follows. Whenever the output of the speed controller saturates, the integral component is reset dynamically with a time constant $T_{t}$ so that the new value is passed as an output.

The error signal $e_{s}$ is generated from the difference of saturation input (or controller output) and saturation output signals. This error signal is then sent to the integrator with gain $\frac{1}{T_{t}}$. The signal $e_{s}$ is equal to value of zero whenever the saturation does not occur and equals to some other values when saturation does happen. This breaks the normal loop, which is then restored when the integrator output is brought to value so that input to the integrator becomes zero.

Input to the integrator is:

$$
\frac{1}{T_{t}} e_{s}+\frac{K}{T_{i}} e=0
$$

where e is the tracking error.

Thus, during the steady state:

$$
e_{s}=-\frac{K T_{t}}{T_{i}} e
$$

where $e_{s}$ is equal to $u-v$, where $\mathrm{v}$ is the saturation input and $\mathrm{u}$ is the saturation output.

$$
v=u_{l i m}+\frac{K T_{t}}{T_{i}} e
$$

where $u_{\text {lim }}$ represents the saturating value.

Therefore, the integrator will not be winding up. The output of the controller is reset according to the feedback gain $\frac{1}{T_{t}}$, where $T_{t}$ is the time constant, which states integral reset period.

For PID anti-windup speed controller the control signal has a proportional band for which the actuator does not saturate. The control signal equation is:

$$
u=K\left(b y_{s p}-y\right)+I-K T_{d} \frac{d y}{d t}
$$

where $b$ is the set point weight.

Then the process output will be:

$$
y_{s p}=y+T_{d} \frac{d y}{d t}
$$

So the proportional band will have interval of:

$$
\begin{aligned}
& y_{l}=b y_{s p}+\frac{I-u_{\text {max }}}{K} \\
& y_{h}=b y_{s p}+\frac{I-u_{\text {min }}}{K}
\end{aligned}
$$

where the actuator saturates for the $u_{\max }$ and $u_{\min }$, which represent control signal values. The operation of the controller will be linear if the response lies in the interval of proportional band. On the contrary, when the control signal does not correspond to the proportional band interval, it saturates. However, this process is not used because the controller which is under consideration is of PI type.

There are many hybrid PI controllers (fuzzy logic, neural network, sliding mode control, etc.) that have been published. However, they are too complicated to 
implement. Recently, many publications focus on 2DOF PI control.

In this paper, back-calculation and tracking approach coupled with the simple 2DOF design was applied to IPMSM speed controller via MATLAB/Simulink simulation. Simulation results are shown to demonstrate the performance of the proposed speed controller.

\section{Simulation ReSUlts AND ANALysis}

The simulation was conducted using Matlab/Simulink software program. Figure 1 represents Simulink model of the whole control loop of IPMSM. The control loop consists of two controllers: speed control loop and current control loop. The goal of the paper was to design IPMSM speed controller.

Figure 2 illustrates the mathematical model of IPMSM. Nominal parameters of the motor are listed in Table I. The mathematical scheme of PI anti-windup speed controller based on feedforward compensation and back calculation is presented in Figure 3. The mathematical scheme of the conventional PI speed controller is shown in Figure 4. Figure 5 shows "C_controller" PI-PI current controller, outputs of which are fed to "Controller" diagram block. "Controller" diagram block is exhibited in Figure 6, where it adds up feedforward and feedback components to obtain control inputs $V_{q s}$ and $V_{d s}$. After some transformations, these control inputs are sent to IPMSM.

\section{A. Simulation setup and conditions}

Set point weighting $\mathrm{b}$ was set to 0.3 . PI gains were chosen according to the tuning rule described in [7]. In the paper, the bandwidths of the PI speed controller and damping coefficient are chosen as $\omega_{s}=2 \pi \cdot 12 \mathrm{rad} / \mathrm{s}$ and 12 , respectively. Therefore, the following tuning constants are obtained: $K=0.038674, T_{i}=0.0188$, and $\mathrm{Tt}$ was set equal to $K$.

Table II illustrates three scenarios to show the performance of designed PI 2-DOF anti-windup speed controller and compare it with conventional PI speed controller. Under Scenario 1, load torque maintains 1 N.m and the speed varies from 900 to $-900 \mathrm{r} / \mathrm{min}$ and returns to $900 \mathrm{r} / \mathrm{min}$. Then, during Scenario 2 load torque maintains 1 N.m and the speed varies from 500 to $-500 \mathrm{r} / \mathrm{min}$ and returns to $500 \mathrm{r} / \mathrm{min}$. Finally, under Scenario 3 reference speed maintains $900 \mathrm{r} / \mathrm{min}$ and the load torque varies from 1 N.m to 1.5 N.m and returns to 1.0 N.m.

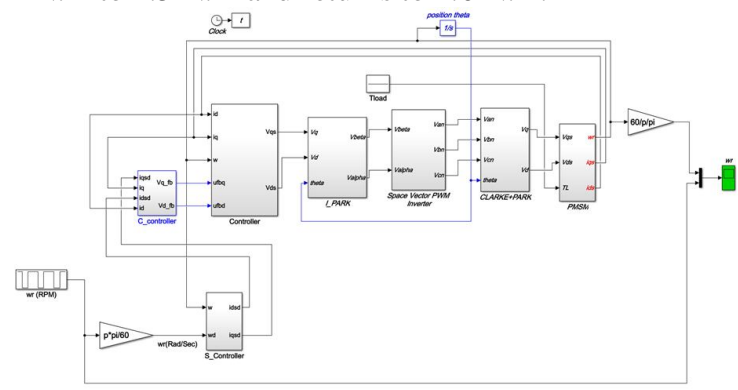

Figure 1. Overall Simulink model of IPMSM control loop

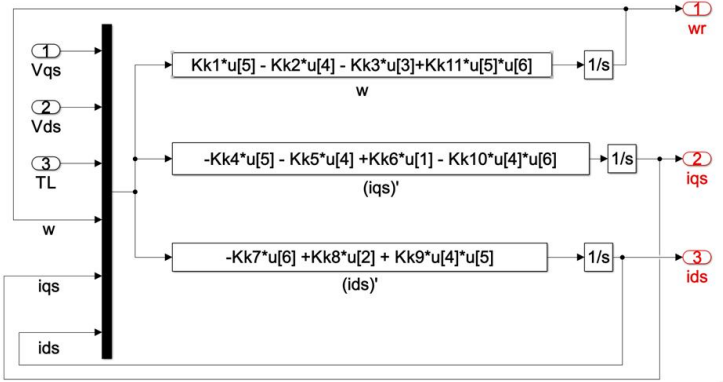

Figure 2. Simulink model of IPMSM

Table I. IPMSM Drive parameters

\begin{tabular}{|l|l|l|l|}
\hline Symbol & Meaning & Value & Unit \\
\hline$P_{\text {rated }}$ & Rated power & 390 & $\mathrm{~W}$ \\
\hline$p$ & Number of poles & 4 & - \\
\hline$R_{s}$ & Stator resistance & 2.48 & $\mathrm{Ohm}$ \\
\hline$L_{q}$ & q-axis inductance & 113.91 & $\mathrm{mH}$ \\
\hline$L_{d}$ & d-axis inductance & 74.98 & $\mathrm{mH}$ \\
\hline$\lambda_{m}$ & Magnet flux linkage & 0.193 & $\mathrm{~V} \cdot \mathrm{s} / \mathrm{rad}$ \\
\hline$J$ & $\begin{array}{l}\text { Equivalent friction } \\
\text { coefficient }\end{array}$ & 0.00042 & $\mathrm{~kg} \cdot \mathrm{m}^{2}$ \\
\hline$B$ & Viscous friction coefficient & 0.0001 & $\mathrm{~N} \cdot \mathrm{m} \cdot \mathrm{s} / \mathrm{rad}$ \\
\hline$V_{d c}$ & dc-link voltage & 295 & $\mathrm{VDC}$ \\
\hline$f_{s}$ & PWM switching frequency & 5 & $\mathrm{kHz}$ \\
\hline
\end{tabular}

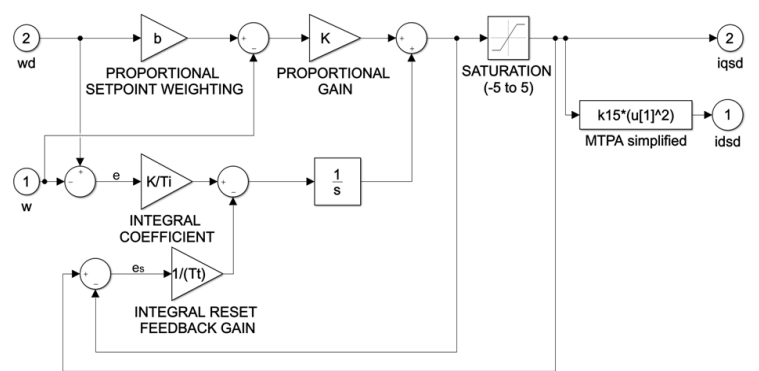

Figure 3. Simulink model of proposed PI anti-windup speed controller

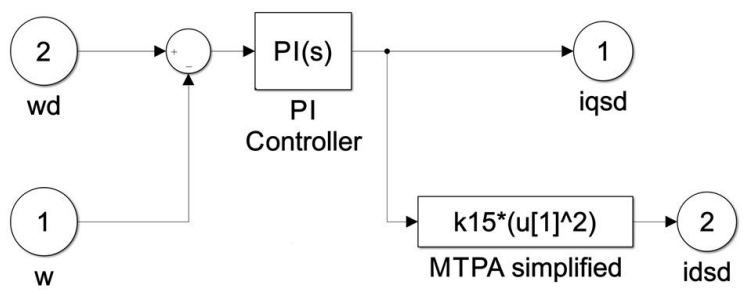

Figure 4. Simulink model of conventional PI speed controller 


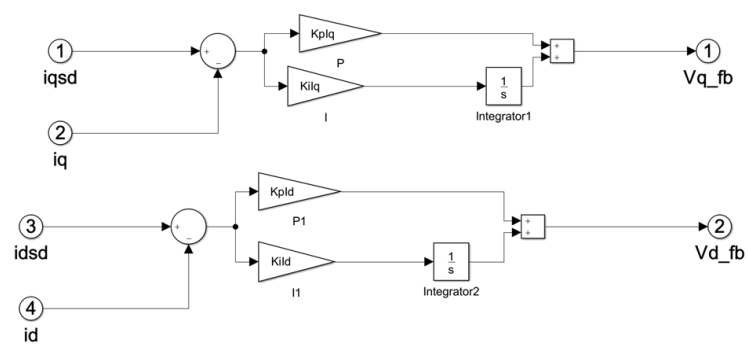

Figure 5. Simulink model of PI-PI current controller

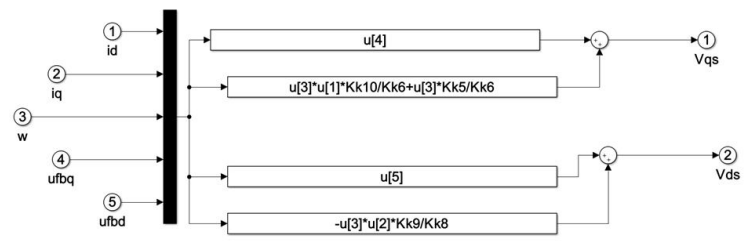

Figure 6. Simulink model for calculating control inputs $V_{q s}$ and $V_{d s}$

Table II. Testing conditions

\begin{tabular}{|l|l|l|}
\hline Scenario & Reference rotor speed $\mathrm{w}_{\mathrm{d}}(\mathrm{r} / \mathrm{min})$ & Load torque $\mathrm{T}_{\mathrm{L}}\left(\mathrm{N}^{*} \mathrm{~m}\right)$ \\
\hline 1 & $900=>-900=>900$ & 1.0 \\
\hline 2 & $500=>-500=>500$ & 1.0 \\
\hline 3 & 900 & $1.0=>1.5=>1.0$ \\
\hline
\end{tabular}

\section{B. Simulation results}

Figures 7(a)-12(a), 7(b)-12(b), 7(c)-12(c), 7(d)-12(d) and 7(e)-12(e) demonstrate speed response, q-axis current $i_{q s}$, d-axis current $i_{d s}$, q-axis voltage $V_{q s}$ and d-axis voltage $V_{d s}$ waveforms, respectively, for designed and conventional speed controllers under all three scenarios.

Scenario 1 was introduced to illustrate the stability of the designed controller. Figure 7(a) shows that the system remains stable after a sudden change of rotor desired speed from 900 to $-900 \mathrm{r} / \mathrm{min}$. Contrary, conventional PI controller becomes unstable (Figure 8(a)).

Considering Scenario 2, conventional speed controller has significant overshoots of $3.99 \%, 68 \%$ and $115.2 \%$ (Figure 10(a)). On the other hand, the proposed controller does not exhibit overshoots during a positive speed change, but it still shows $6.52 \%$ overshoot after 500 to $500 \mathrm{r} / \mathrm{min}$ speed change (Figure 9(a)). Moreover, the settling time was improved from $0.24 \mathrm{~s}$ to $0.11 \mathrm{~s}$ (during 500 to $-500 \mathrm{r} / \mathrm{min}$ speed change) and from $0.24 \mathrm{~s}$ to $0.09 \mathrm{~s}$ (during -500 to $500 \mathrm{r} / \mathrm{min}$ speed change).
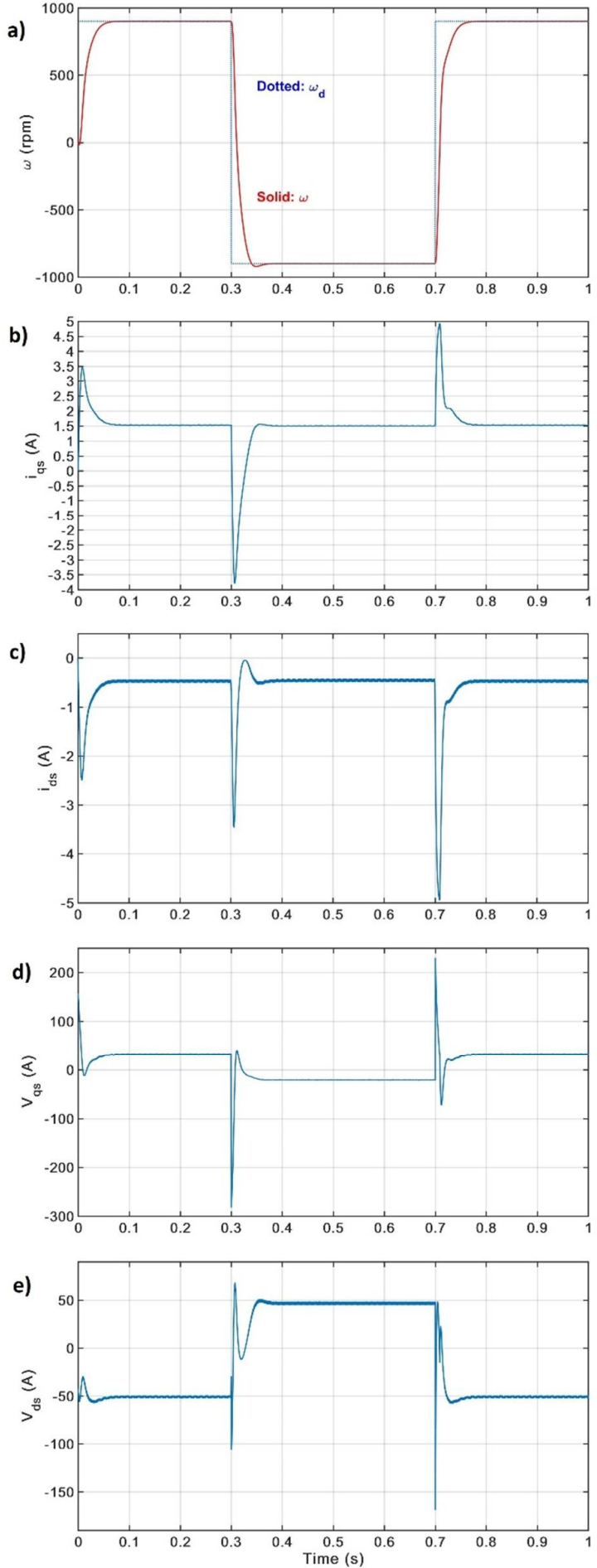

Figure 7. a) Simulation of IPMSM with PI anti-windup controller during set-point changes between $900 \mathrm{rpm}$ and $-900 \mathrm{rpm} \mathrm{b}$ ) Simulation result of $i_{q s}$ current c) Simulation result of $i_{d s}$ current d) Simulation result of $V_{q s}$ voltage e) Simulation result of $V_{d s}$ voltage 

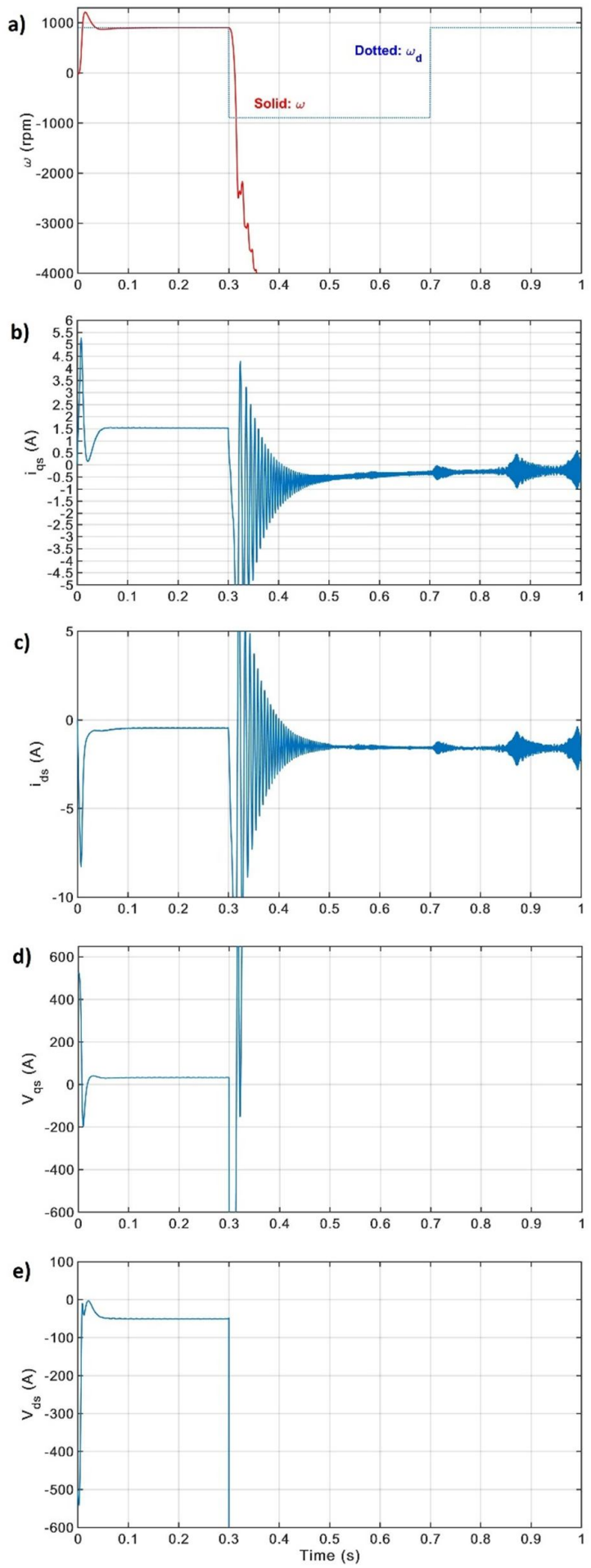

Figure 8. a) Simulation of IPMSM with conventional controller during set-point changes between $900 \mathrm{rpm}$ and $-900 \mathrm{rpm}$ b) Simulation result of $i_{q s}$ current c) Simulation result of $i_{d s}$ current d) Simulation result of $V_{q s}$ voltage e) Simulation result of $V_{d s}$ voltage a)

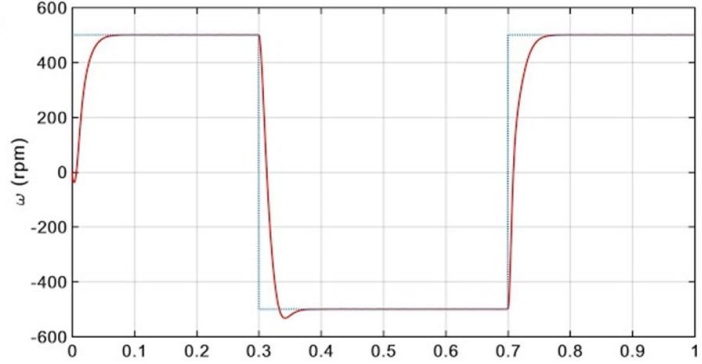

b)

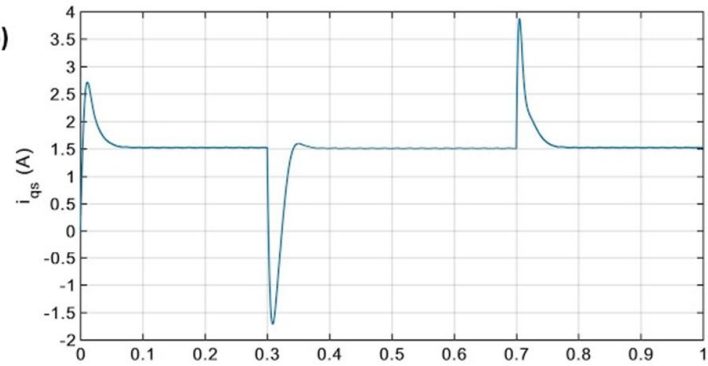

c)
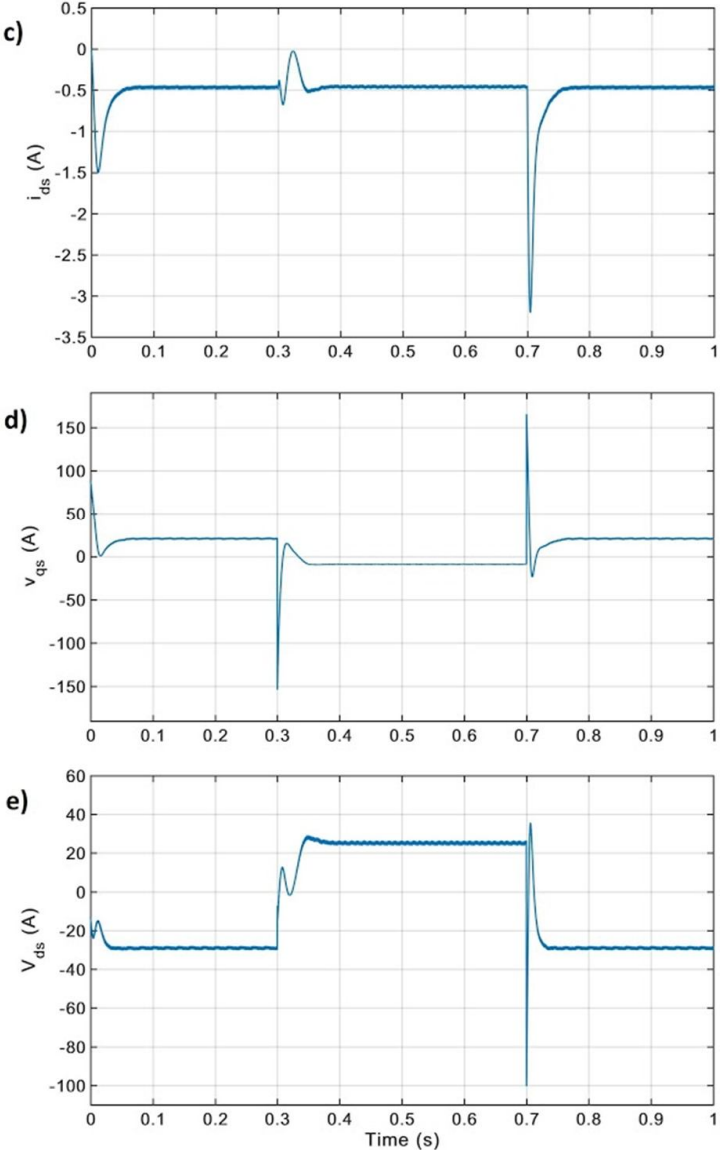

Figure 9. a) Simulation of IPMSM with PI anti-windup controller during set-point changes between $500 \mathrm{rpm}$ and $-500 \mathrm{rpm}$ b) Simulation result of $i_{q s}$ current c) Simulation result of $i_{d s}$ current d) Simulation result of $V_{q s}$ voltage e) Simulation result of $V_{d s}$ voltage 

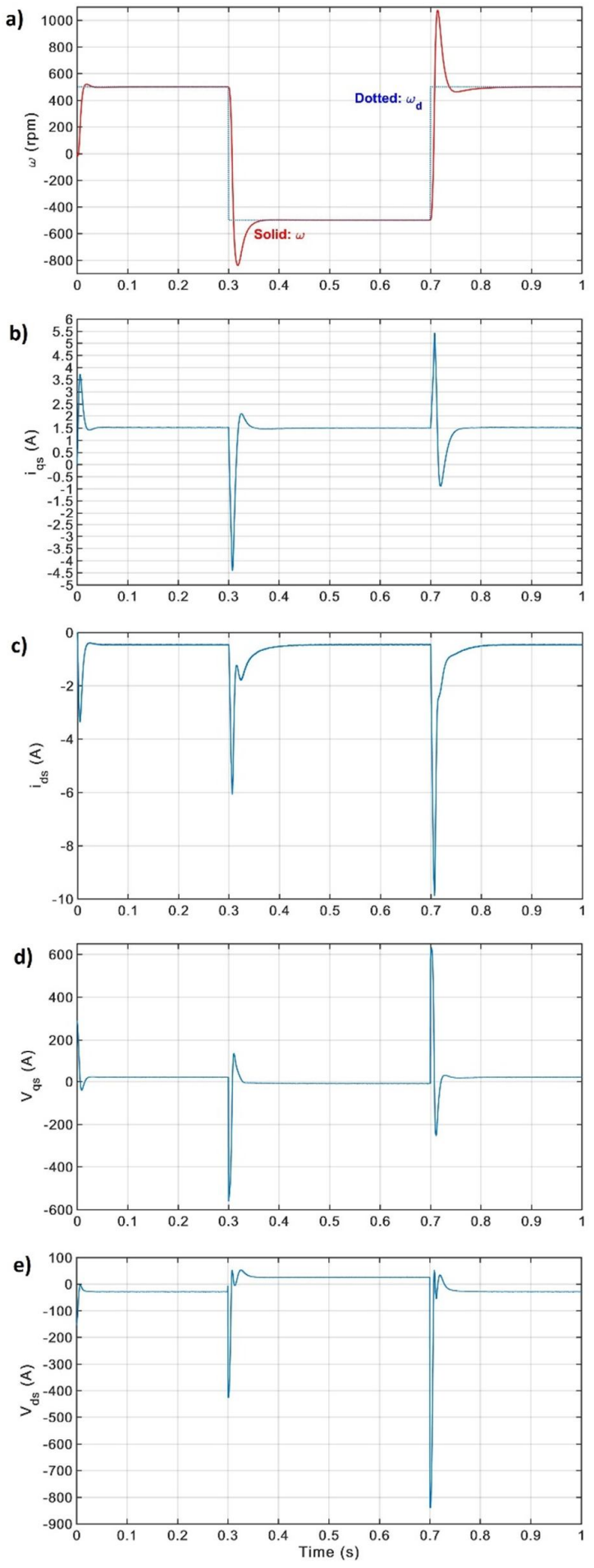

Figure 10. a) Simulation of IPMSM with conventional controller during set-point changes between $500 \mathrm{rpm}$ and $-500 \mathrm{rpm} \mathrm{b}$ ) Simulation result of $i_{q s}$ current c) Simulation result of $i_{d s}$ current rpm d) Simulation result of $V_{q s}$ voltage e) Simulation result of $V_{d s}$ voltage
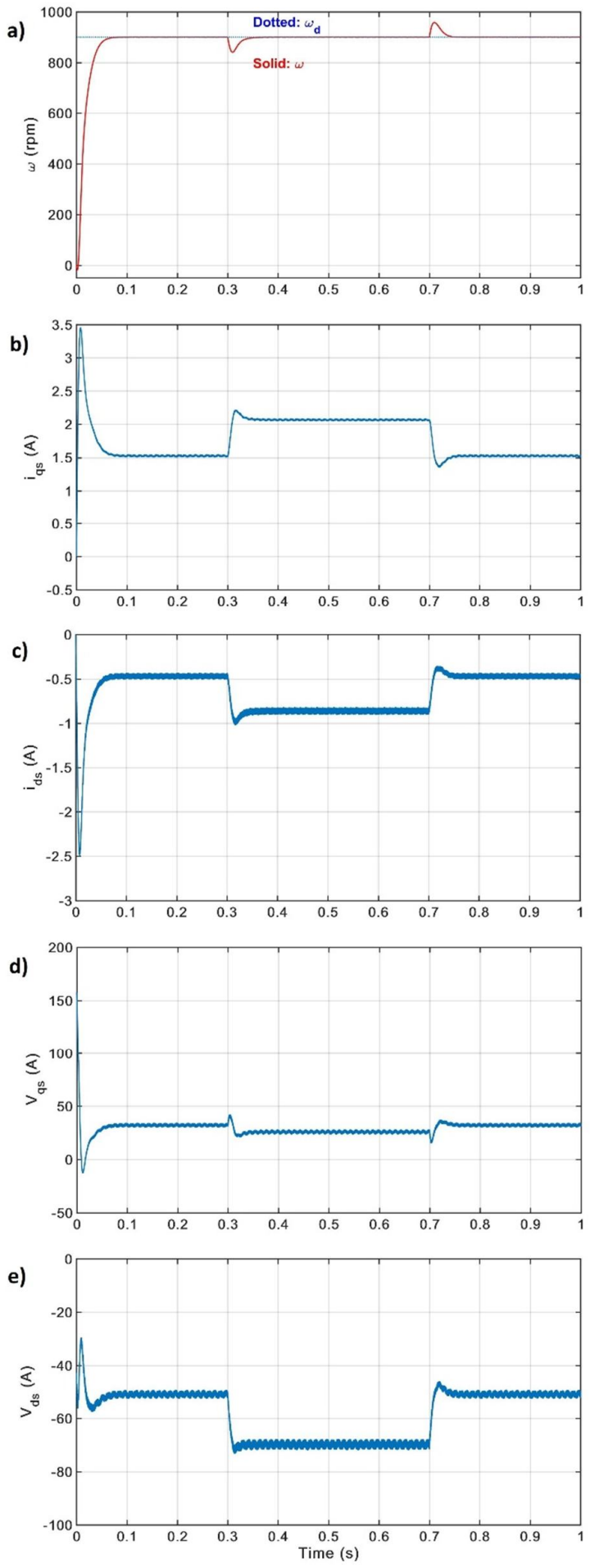

Figure 11. a) Simulation of IPMSM with PI anti-windup controller during load-torque changes introduced b) Simulation result of $i_{q s}$ current c) Simulation result of $i_{d s}$ current d) Simulation result of $V_{q s}$ voltage e) Simulation result of $V_{d s}$ voltage 


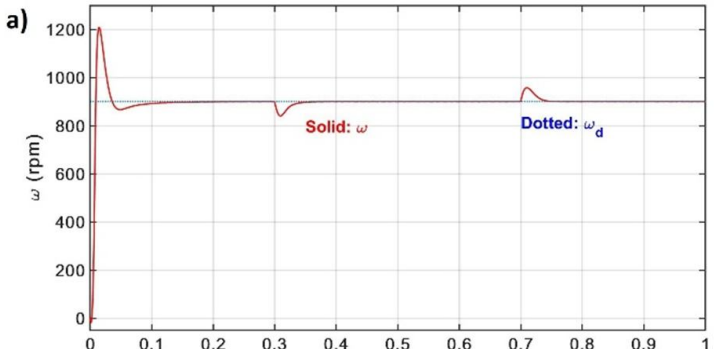

b)

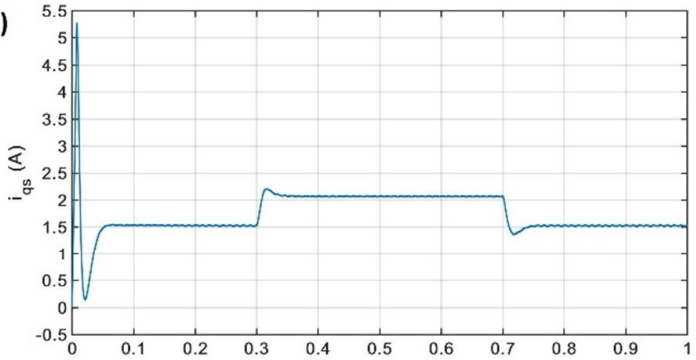

c)

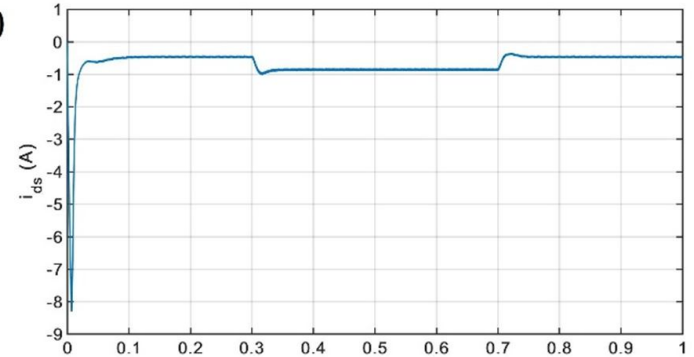

d)

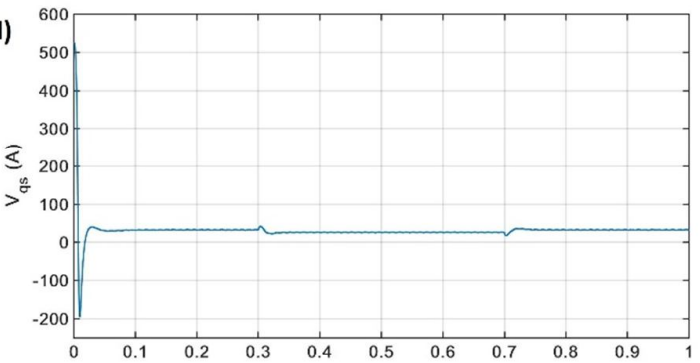

e)

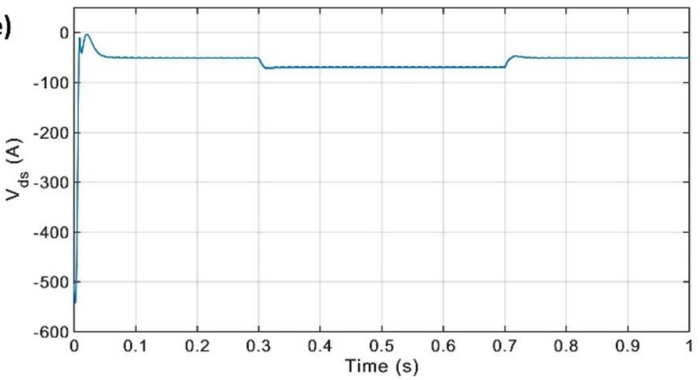

Figure 12. a) Simulation of IPMSM with PI conventional controller during load-torque changes introduced b) Simulation result of $i_{q s}$ current c) Simulation result of $i_{d s}$ current d) Simulation result of $V_{q s}$ voltage e) Simulation result of $V_{d s}$ voltage

\section{Analysis}

First simulation trials were conducted by setting reference speed values from 900 at 0 seconds to -900 at 3 seconds and, again, to 900 at 7 seconds. PI anti-windup speed controller exhibited significantly better results with smooth speed tracking without overshoots. The simulation result is shown in Figure 7(a).

On the other hand, conventional PI speed controller became unstable at 3 seconds when reference speed changed from $900 \mathrm{rpm}$ to $-900 \mathrm{rpm}$. The simulation result is shown in Figure 8(a). Moreover, it can be noted that $i_{q s}$ and $i_{d s}$ currents become unstable at 3 seconds (Figures 8(b)-(c)) as well as voltages $V_{q s}$ and $V_{d s}$ (Figures 8(d)-(e)).

Therefore, for a fair comparison, the reference speed changed from 500 at 0 seconds to -500 at 3 seconds and 500 at 7 seconds. Simulation result with PI anti-windup speed controller is presented in Figure 9(a). At lower speeds, advanced speed controller shows great performance with smooth tracking and no overshoots at $500 \mathrm{rpm}$ and insignificant one during $-500 \mathrm{rpm}$ speed tracking.

The conventional speed controller demonstrated stable response during 500 and $-500 \mathrm{rpm}$, but high overshoots occurred during $-500 \mathrm{rpm}$ and $500 \mathrm{rpm}$ references speed changes. The simulation result is shown in Figure 10(a).

Nevertheless, designed controller shows no change in terms of robustness to load torque or parameter variations (changes in motor inertia $\mathbf{J}$ was introduced as an example). Figures 11(a) and 12(a) present the simulation results.

\section{CONCLUSION}

This paper proposes PI anti-windup control of IPMSM based on feedforward compensation. The testing of this advanced controller was done in Matlab/Simulink simulation program using mathematical representations of IPMSM and both controllers. Overall, the proposed antiwindup PI speed controller with set-point weighting demonstrates better results in terms of set-point tracking with fast response and stability during reference speed changes in comparison with a conventional PI controller. Although, further work should be conducted to improve robustness for load torque and motor parameter variations.

\section{REFERENCES}

[1] A. V. Sant, K. R. Rajagopal and N. K. Sheth, "Permanent Magnet Synchronous Motor Drive Using Hybrid PI Speed Controller With Inherent and Noninherent Switching Functions," in IEEE Transactions on Magnetics, vol. 47, no. 10, pp. 4088-4091, Oct. 2011. doi: 10.1109/TMAG.2011.2159831

[2] B. T. Zhang and Y. Pi, "Robust fractional order proportion-plusdifferential controller based on fuzzy inference for permanent magnet synchronous motor," in IET Control Theory \& Applications, vol. 6, no. 6, pp. 829-837, April 12 2012. doi: 10.1049/iet-cta.2011.0412

[3] Choi, H. H., et al. "Precise PI speed control of permanent magnet synchronous motor with a simple learning feedforward compensation." Electrical Engineering99.1 (2017): 133-139. 
[4] Espina, Jordi, et al. "Speed anti-windup PI strategies review for field oriented control of permanent magnet synchronous machines." Compatibility and Power Electronics, 2009. CPE'09.. IEEE, 2009.

[5] J. W. Jung, V. Q. Leu, T. D. Do, E. K. Kim and H. H. Choi, "Adaptive PID Speed Control Design for Permanent Magnet Synchronous Motor Drives," in IEEE Transactions on Power Electronics, vol. 30, no. 2, pp. 900-908, Feb. 2015. doi: 10.1109/TPEL.2014.2311462

[6] K. Astrom and T. Hägglund, Advanced PID control. Research Triangle Park, N.C.: ISA, 2006

[7] P. Kshirsagar et al., "Implementation and Sensorless Vector-Control Design and Tuning Strategy for SMPM Machines in Fan-Type Applications," in IEEE Transactions on Industry Applications, vol. 48, no. 6, pp. 2402-2413, Nov.-Dec. 2012. doi: 10.1109/TIA.2012.2227135

[8] T. D. Do, S. Kwak, H. H. Choi and J. W. Jung, "Suboptimal Control Scheme Design for Interior Permanent-Magnet Synchronous Motors: An SDRE-Based Approach," in IEEE Transactions on Power Electronics, vol. 29, no. 6, pp. 3020-3031, June 2014. doi: 10.1109/TPEL.2013.2272582

[9] H. Lin, K. Hwang and B. Kwon, "An Improved Flux Observer for Sensorless Permanent Magnet Synchronous Motor Drives with Parameter Identification", Journal of Electrical Engineering and Technology, vol. 8, no. 3, pp. 516-523, 2013.

[10] M. Uddin, M. Abido and M. Rahman, "Development and Implementation of a Hybrid Intelligent Controller for Interior Permanent-Magnet Synchronous Motor Drives", IEEE Transactions on Industry Applications, vol. 40, no. 1, pp. 68-76, 2004.
[11] R. Rebeiro and M. Uddin, "Performance Analysis of an FLC-Based Online Adaptation of Both Hysteresis and PI Controllers for IPMSM Drive", IEEE Transactions on Industry Applications, vol. 48, no. 1, pp. 12-19, 2012.

[12] Gou-Jen Wang, Chuan-Tzueng Fong and K. Chang, "Neuralnetwork-based self-tuning PI controller for precise motion control of PMAC motors", IEEE Transactions on Industrial Electronics, vol. 48, no. 2, pp. 408-415, 2001.

[13] C. Xia, Y. Yan, P. Song, and T. Shi, "Voltage disturbance rejection for matrix converter-based PMSM drive system using internal model control," IEEE Trans. Ind. Electron., vol. 59, no. 1, pp. 361372, Jan. 2012

[14] M. A. Rahman, M. Vilathgamuwa, M. N. Uddin, and K. J. Tseng, "Nonlinear control of interior permanent-magnet synchronous motor," IEEE Trans. Ind. App., vol. 39, no. 2, pp. 408-415, Mar./Apr. 2003.

[15] V. Leu, H. Choi and J. Jung, "Fuzzy Sliding Mode Speed Controller for PM Synchronous Motors With a Load Torque Observer", IEEE Transactions on Power Electronics, vol. 27, no. 3, pp. 1530-1539, 2012.

[16] M. Uddin and R. Rebeiro, "Online Efficiency Optimization of a Fuzzy-Logic-Controller-Based IPMSM Drive", IEEE Transactions on Industry Applications, vol. 47, no. 2, pp. 1043-1050, 2011.

[17] M. Preindl and S. Bolognani, "Model predictive direct speed control with finite control set of PMSM drive systems," IEEE Trans. Power Electron., vol. 28, no. 2, pp. 1007-1015, Feb. 2013. 